Sustainability, Agri, Food and Environmental Research, 2015, 3(1): 47-49

ISSN: 0719-3726

Carta al editor

\title{
Situación actual sobre las plantaciones forestales
}

\author{
Roberto Cornejo Espósito
}

Presidente Nacional Colegio Ingenieros Forestales, San Isidro 22, oficina 503, Santiago de Chile, email: robertocornejoe@gmail.com

El 2012, último año de vigencia de la bonificación forestal contemplada en la Ley 20.488, la tasa de forestación en el país fue de 17.150 hectáreas. El año 2013, ya sin bonificación, la forestación se redujo a 6.608 hectáreas (CONAF: Informe técnico plantaciones Forestales establecidas durante el año 2013) y en el año 2014 se forestaron cerca de 5.000 hectáreas forestadas (CONAF, información entregada por el departamento de plantaciones, Com. Pers.), que significa una caída de más del $65 \%$ de la superficie plantada con respecto al último año con presencia del D1 701. Las cifras dan cuenta del evidente impacto que la ausencia de bonificación genera en los propietarios de terrenos susceptibles de ser plantados. La disminución y caída continua de las tasas de la forestación es dramática, si se compara con las 70.000 hectáreas por año que se forestaban en décadas pasadas. Evidentemente en Chile ahora ya no se están plantando nuevos terrenos.

La caída de las tasas de forestación anuales es muy probable que impacte, no solo en el abastecimiento futuro de madera para los mismos pequeños propietarios y la pequeña y mediana industria forestal, sino también afectará la cadena de valor de la forestación (viveristas, contratistas plantadores, obreros forestales, profesionales consultores). Sin olvidar el impacto ambiental negativo que significa el mantener del orden de dos millones de hectáreas con suelos desnudos en proceso de degradación y empobrecimiento.(INFOR, 2014, 2015)

Si esto ya es preocupante, agrava el escenario futuro el hecho que la nueva prórroga de las bonificaciones forestales que se planteó el programa de gobierno actual, está siendo cuestionada por algunos parlamentarios de gobierno (CIFAG, 2015a). En efecto, utilizando una serie de argumentos equivocados, pero comunicados en forma convincente, han construido una narrativa contra los cultivos forestales, en particular pino insigne y eucaliptus, que hace peligrar la continuidad de este instrumento de fomento forestal. Es cierto que los beneficios del Dl. 701 principalmente se concentran en las grandes empresa forestales, pero debemos tener en cuenta que las casi 2.000.000 de hectáreas degradadas y mayormente erosionadas que se encuentran sin vegetación, están en 
Sustainability, Agri, Food and Environmental Research, 2015, 3(1): 47-49 ISSN: 0719-3726

manos de pequeños y medianos propietarios ubicados en los sectores menos interesantes para las empresas (INFOR, 2015). Se debe de tener en cuenta que la pequeña y mediana empresa forestal, tales como aserraderos, cajoneras y estas plantaciones pueden cubrir el mercado que se necesita para el impulso de las pequeñas y medianas empresas forestales (CIFAG, 2015b). Por otra parte, quienes son los llamados a defender los aciertos de un instrumento que ha permitido recuperar millones de hectáreas de territorio degradado por una agricultura no sustentable, les ha faltado la convicción necesaria para hacerlo

En la antesala de una nueva discusión en el Congreso respecto a la continuidad de este instrumento, los cuestionamientos y las presiones buscan, desconociendo al programa de gobierno de la Presidenta Bachelet en materia forestal, lograr alteraciones sustanciales al instrumento de fomento, excluyendo de la bonificación las plantaciones con especies exóticas. Esta exclusión es motivada por consideraciones ambientales mal entendidas que, paradójicamente, parecen escapárseles a los propietarios de los terrenos a forestar, ya que son ellos los que en un porcentaje mayoritario de los casos optan por dichas especies para forestar sus predios. No son los pequeños propietarios quienes deban pagar los costos de los desvelos ambientalistas extremos de algunos parlamentarios, ni quienes deberían verse forzados a endeudarse para plantar especies nativas que tendrán dificultades de sobrevivencia en terrenos degradados, dado que ya no están las condiciones de suelo y clima de las especies originarias, ni existe claridad de mercado futuro, además de crecer en más del doble del tiempo de rotación de una especie comercial ya probada (CIFAG, 2015c). En este contexto, se sugiere a todos los actores involucrados lograr una institucionalidad apegada a la situación actual del sector forestal con el fin de lograr una máxima productividad que sea social y ambientalmente sustentable.

\section{REFERENCIAS}

Corporación Nacional Forestal (CONAF) Informe técnico plantaciones Forestales establecidas durante el año 2013.

Instituto Forestal- INFOR, 2014. Anuario Forestal. Boletín Estadístico 144. Santiago de Chile. 166 p.

Instituto Forestal- INFOR, 2015. http://wef.infor.cl/destacados.php (visitado el 07 de febrero de 2015). 
Sustainability, Agri, Food and Environmental Research, 2015, 3(1): 47-49

ISSN: 0719-3726

Colegio de Ingenieros Forestales, Asociación Gremial - CIFAG, 2015a. http://www.cifag.cl/_file/file_161_nota\%20informativa\%20cifag\%20meo\%202015.pdf (visitado el 07 de febrero de 2015).

Colegio de Ingenieros Forestales, Asociación Gremial - CIFAG, $2105 \mathrm{~b}$. http://www.cifag.cl/ file/file 161 carta\%20abierta\%20diputados\%20d.1.\%20701.pdf (visitado el 07 de febrero de 2015).

Colegio de Ingenieros Forestales, Asociación Gremial - CIFAG, 2105c. http://www.cifag.cl/_file/file_161_propuesta\%20sector\%20forestal\%20chileno.pdf (visitado el 07 de febrero de 2015). 